\title{
In Response
}

Dear Sir:

Monge-Maillo and López-Vélez address the important issues of whether topical paromomycin treatments for cutaneous leishmaniasis (CL) achieve a higher cure rate when combined with another antileishmanial agent and the risk of mucosal leishmaniasis when cutaneous disease is treated locally.

We agree with these writers that combinations of paromomycin with other drugs are likely to be more effective than paromomycin alone. Although the writers focus on a combination with methylbenzethonium chloride (MBCL), we focus on a combination with gentamicin given significant adverse reactions noted with use of $\mathrm{MBCL}^{1,2}$ strong animal data for paromomycin-plus-gentamicin, ${ }^{3}$ and the trend to increased efficacy from paromomycin-plus-gentamicin versus paromomycinalone in the phase 2 study under discussion. ${ }^{4}$ When the data from our present phase 3 trial of paromomycin-plus-gentamicin (WR 279,396) versus paromomycin alone for Leishmania panamensis CL in Panama is known, others may wish to follow the suggestion of the letter writers and compare the most effective product in our trial to paromomycin-plus-MBCL but this undertaking should take into consideration the safety profile of these different formulations in addition to efficacy.

The issue of whether mucosal leishmaniasis consequent to CL is more likely after local therapy than systemic therapy is without a simple answer ${ }^{5}$ but we are following the World Health Organization $(2010)^{6}$ current recommendation that local treatment is appropriate for all CL species, however, should be based on the benefit-risk considerations for each individual patient.

Finally, let us note that when we wrote that "Paromomycin $15 \%$ plus MBCL $12 \%$ has not been evaluated alone against L. panamensis," we meant in a study in which only L. panamensis was documented to be the infecting parasite. For Krause and Kroger, ${ }^{7}$ only two parasites were identified as L. panamensis. For Armijos and others ${ }^{8}$ parasites were identified to the subgenus level but not to the species level.

Max Grogl

Division of Experimental Therapeutics

Walter Reed Army Institute of Research

Silver Spring, Maryland

E-mail:max.grogl@gmail.com

\author{
Nestor Sosa \\ Instituto Conmemorativo Gorgas de Estudios de la Salud \\ Avenida Justo Arosemena \\ Panama City, Panama \\ Mara Kreishman-Deitrick \\ U.S. Army Medical Materiel Development Activity (USAMMDA) \\ Fort Detrick, Maryland
}

This is an open-access article distributed under the terms of the Creative Commons Attribution License, which permits unrestricted use, distribution, and reproduction in any medium, provided the original author and source are credited.

\section{REFERENCES}

1. Garnier T, Croft SL, 2002. Topical treatment for cutaneous leishmasniasis. Curr Opin Investig Drugs 3: 538-544.

2. International Journal of Toxicology, 1985. Final report on the safety assessment of benzethonium chloride and methylbenzethonium chloride. Int J Toxicol 4: 65-106.

3. Grogl M, Schuster BG, Ellis WY, Berman JD, 1999. Successful topical treatment of murine cutaneous leishmaniasis with a combination of paromomycin (Aminosidine) and gentamicin. J Parasitol 85: 354-359.

4. Sosa N, Capitán Z, Nieto J, Nieto M, Calzada J, Paz H, Spadafora C, Kreishman-Deitrick M, Kopydlowski K, Ullman D, McCarthy WF, Ransom J, Berman J, Scott C, Grogl M, 2013. Randomized, double-blinded, phase 2 trial of WR 279,396 (paromomycin and gentamicin) for cutaneous leishmaniasis in Panama. Am J Trop Med Hyg 89: 557-563.

5. Soto J, Berman J, 2013. Reply to Monge-Maillo et al. Clin Infect Dis 57: 1503-1504.

6. WHO, 2010. Control of the leishmaniases. WHO Technical report series no. 949

7. Krause G, Kroeger A, 1994. Topical treatment of American cutaneous leishmaniasis with paromomycin and methylbenzethonium chloride: a clinical study under field conditions in Ecuador. Trans R Soc Trop Med Hyg 88: 92-94.

8. Armijos RX, Weigel MM, Calvopiña M, Mancheno M, Rodriguez $\mathrm{R}$, 2004. Comparison of the effectiveness of two topical paromomycin treatments versus meglumine antimoniate for new world cutaneous leishmaniasis. Acta Trop 91: 153-160. 